\title{
EVALUATION OF CALCULATED CONNATE WATER SATURATION VALUES IN CASE OF UNCONVENTIONAL ROCK SAMPLES
}

\author{
Ferenc Remeczki \\ PhD student, University of Miskolc, Research Institute of Applied Earth Sciences \\ 3515 Miskolc, Miskolc-Egyetemváros, e-mail: afkremec@uni-miskolc.hu
}

\begin{abstract}
The present study represents possibilities of calculating the connate water saturation - CWS - values of samples from unconventional reservoirs and how to evaluate the obtained result. CWS is an extremely important property of the reservoir rocks. It basically determines the value of the resource and can also predict production technology difficulties. For the samples included in the measurement program, significant or extremely high CWS values were determined. Analysis of the corrected pore size distribution proved to be the most appropriate method for interpreting CWS values, although, it also shows some correlation with the most frequent pore radius - MFPR - and porosity.
\end{abstract}

Keywords: connate water saturation, tight sandstone and marl

\section{Introduction}

The determination of saturation conditions that is the basis of the unconventional hydrocarbon reservoir research, plays a significant role in the PULSE project at the Research Institute of Applied Earth Sciences of the University of Miskolc. Water saturation has an extremely large effect on the productivity of reservoirs, especially in the case of water-wet rocks. The saturation test of unconventional systems is quite complicated because, due to the properties of the available core material, the measurements are often not feasible and need to be corrected or may not be performed at all, in contrast to the measurements on samples from traditional sandstone reservoirs. Given that saturation states are difficult to model, the focus has shifted primarily to the determination of residual water saturation, which, based on field production and measurement experience, appears to be extremely high for these reservoirs.

\section{Tested samples and methods of analysis}

For the examination and determination of the connate water saturation or saturation relations and relative permeability curves, in the case of hydrocarbon reservoirs considered to be essentially conventional, samples with a diameter of $38 \mathrm{~mm}$ and an optimal length of 50 to $70 \mathrm{~mm}$ designed in accordance with the API RP40 standard are used (Figure 1). However, the available core material in the present situation is of limited value and is invaluable due to the costly core drilling operations. As a result of this, two methods are applicable in the Research Institute: measurements with a rock centrifuge and conversion of mercury-gas capillary pressure curves from Mercury injection measurements to water-gas capillary pressure curves.

Measurements with a rock centrifuge, although considered a common practice, is not able to create a sufficient pressure difference in the case of solid sandstone or marl samples, and there is a possibility of permanent damage, making the measurement non-reproducible and destroying the core material. To 
avoid it, Mercury injection measurement was selected. Samples with a volume of 1-2 $\mathrm{cm}^{3}$, which are used for the measurements, can be formed by cutting the sample plug or, if the reproduction is necessary, directly from the drill core a few millimeters apart (Figure 1). This preserves a significant percentage of the core material, as well as the possibility of re-performing other types of measurements.

A significant part of the examined samples comes from the sections of Hunya-1 (2877 - $3177 \mathrm{~m})$, Köröstarcsa-5 (2896 - $3046.2 \mathrm{~m}$ ) and Szabadkígyós-1 (3266 - $3614 \mathrm{~m}$ ) wells crossing the Szolnok Formation. In an earlier part of the research project, it has been presented [1] that the author has already examined Szabadkígyós -1 well giving the basis of this series of tests, but in this case the core sections of the two other wells, taken from deeper, have already reached the Endröd Formation (Hunya-1: 3697 - 3913 m; Köröstarcsa-5: 3227.35 - 3230 m), thus the cores include marl and calcareous marl. In view of the above, the study places greater emphasis on the analysis of samples from Hunya-1 and Köröstarcsa-5 wells, and the results calculated for Szabadkígyós-1 well help to investigate the correlation.

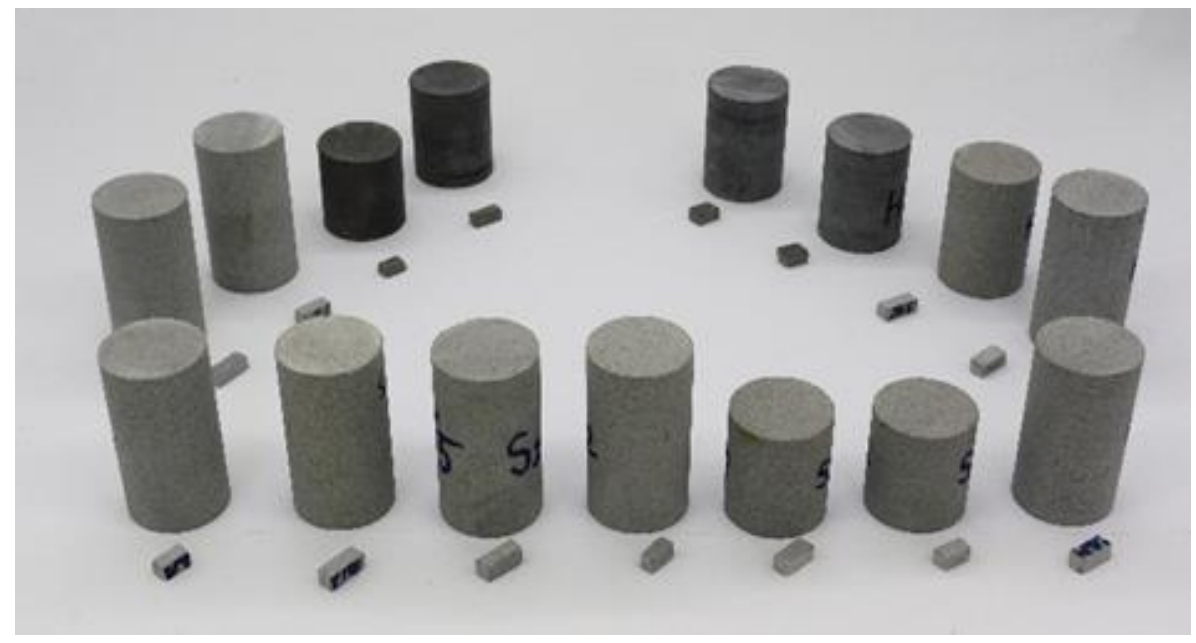

Figure 1. Unconventional samples used during the measurement protocol

\section{Result analysis}

\subsection{Pore size distribution}

Connate water saturation can be calculated from the capillary pressure curves of Mercury injection measurements based on Purcell's model [2]. Capillary pressure values of the water / gas system must be calculated first, which can be done by using the measurement results in the Mercury / gas system. Substituting this into Purcell's equations gives the connate water saturation values. The model can be used with great certainty for samples from unconventional reservoirs, as the only input data is the capillary pressure measured by the instrument, so its accuracy depends on the measurement range of the device. Based on the pore size distribution curves shown below, the measuring range of the instrument is adequate.

The first step is to examine the pore size distribution functions and their changes for a proper reservoir point of view rock type description. This change is shown in Figure 2 for the Hunya-1 well. Pore diameters - from 0.001 to 100 microns - are plotted as a function of cumulative volume of Mercury injected $\left(\mathrm{cm}^{3} / \mathrm{g}\right)$ and relative pore volume $(\%)$. 

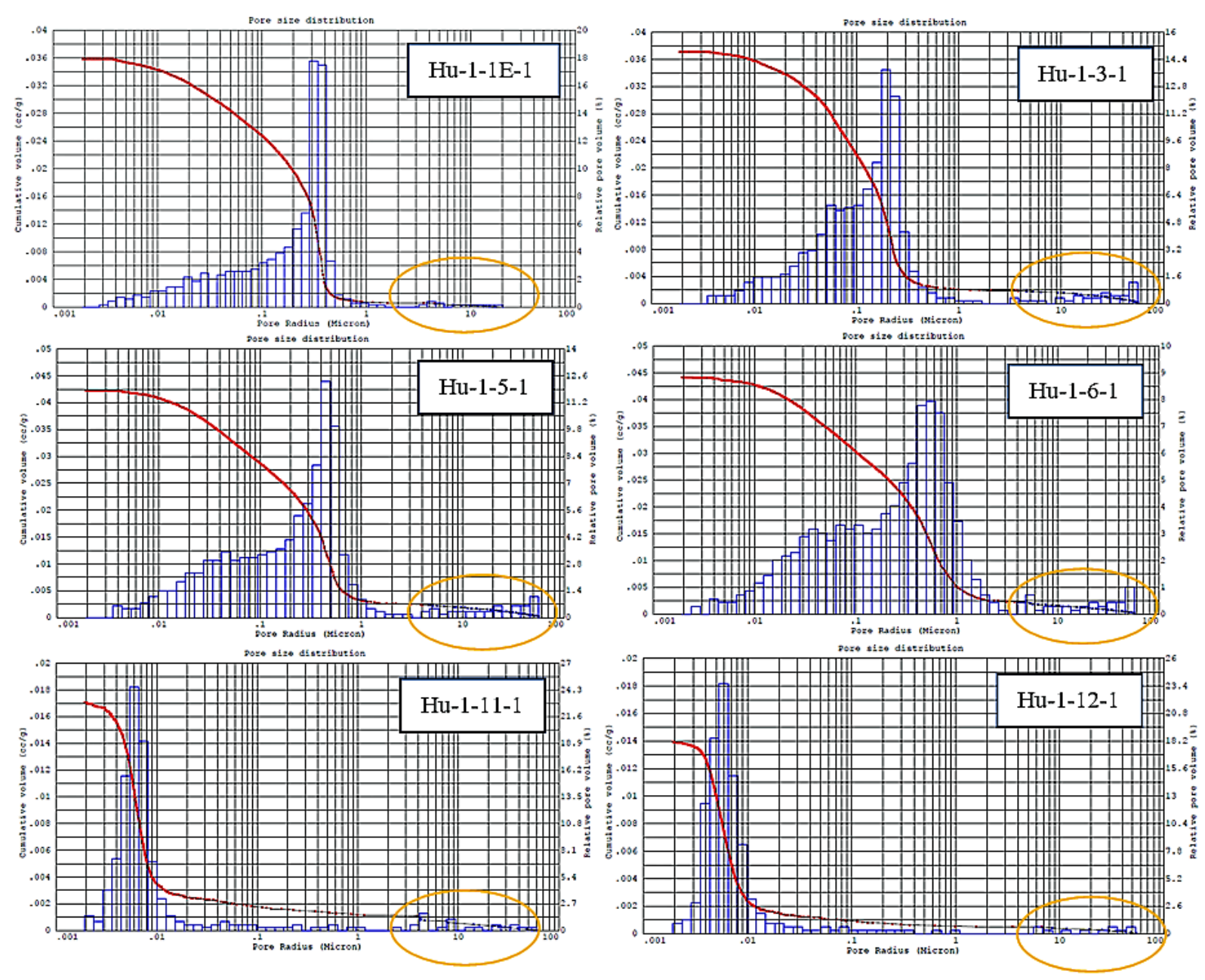

Figure 2. Pore size distribution curves of samples from Hunya-1 well

The increasing values of the series of numbers used in the sample names also indicate an increase in depth for this well. Based on the measurement results, it can be stated that a significant percentage of the pore diameters of sandstone samples are between 0.01 and 1 micron (micrometer), the most common values being between 0.2 and 0.6 . However, marl - calcareous marl specimens have their pore size between 0.001 and 0.01 micron, which is an unusually low range for hydrocarbon reservoirs. It is important to note that, contrary to expectations, the distributions show larger diameter values with increasing depth in sandstone samples. It is also assumed that in the range above 2 microns, microcracks (highlighted with an orange marker circle) appear during the preparation of the samples, caused by the residual stresses released, which can majorly affect the evaluation due to their size. Given that these zones do not characterize the true pore structure of the rock, they have been removed from the model input data. Figure 3 shows the measurement results of the samples from the Köröstarcsa-5 well. 

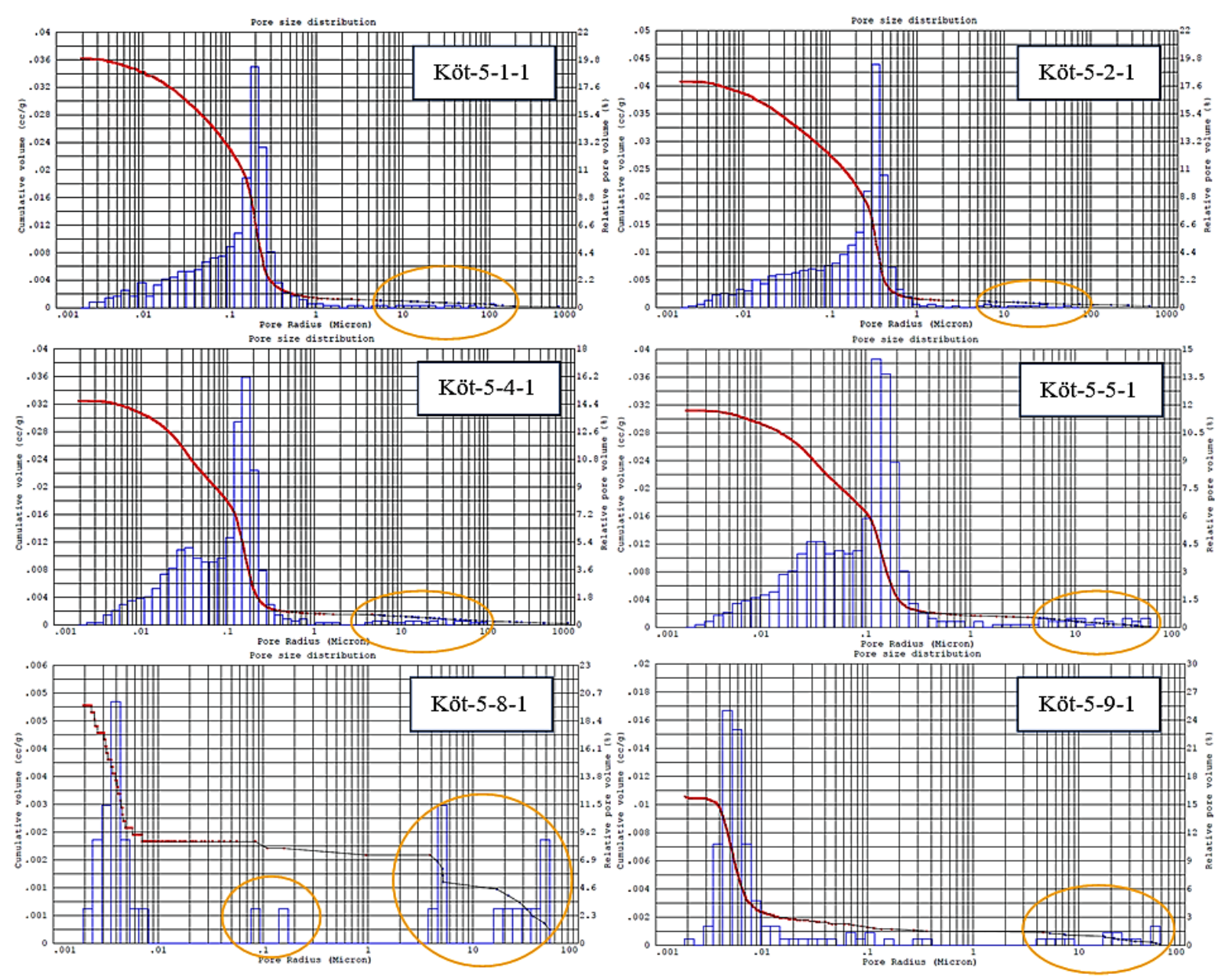

Figure 3. Pore size distribution curves of samples from Köröstarcsa-5 well

In case of the second model well, the pore size diameters of the sandstone samples are mainly similarly to the previous well - between 0.01 and 1 micron and the most significant range is between 0.1 and 0.5 micron. The amount of microcracks appearing as a result of the preparation is not significant and thus the evaluation is barely affected by it. However, in the case of marls, values between 0.001 and 0.01 microns are again specifying the characteristics of the pore size distribution and the presence of microcracks can greatly influence the analysis, especially with respect to Köt-5-8-1 sample.

Among the cores originated from Szabadkígyós-1 well, there is no representation of Endröd Formation samples, but they are perfectly suitable to study the correlation of sandstone samples. Comparing the data reported in the author's previous presentation [1], which were measured and calculated at an earlier stage of the same measurement protocol, the range of sandstone values presented in this study is the same as from Szabadkígyós-1 well, and the nature of microcracks can be also qualified similar. 


\subsection{Connate water saturation determination}

The measuring range of the instrument proved to be adequate, thus the Mercury / gas capillary pressure curves (Figure 4) can be used with great reliability.
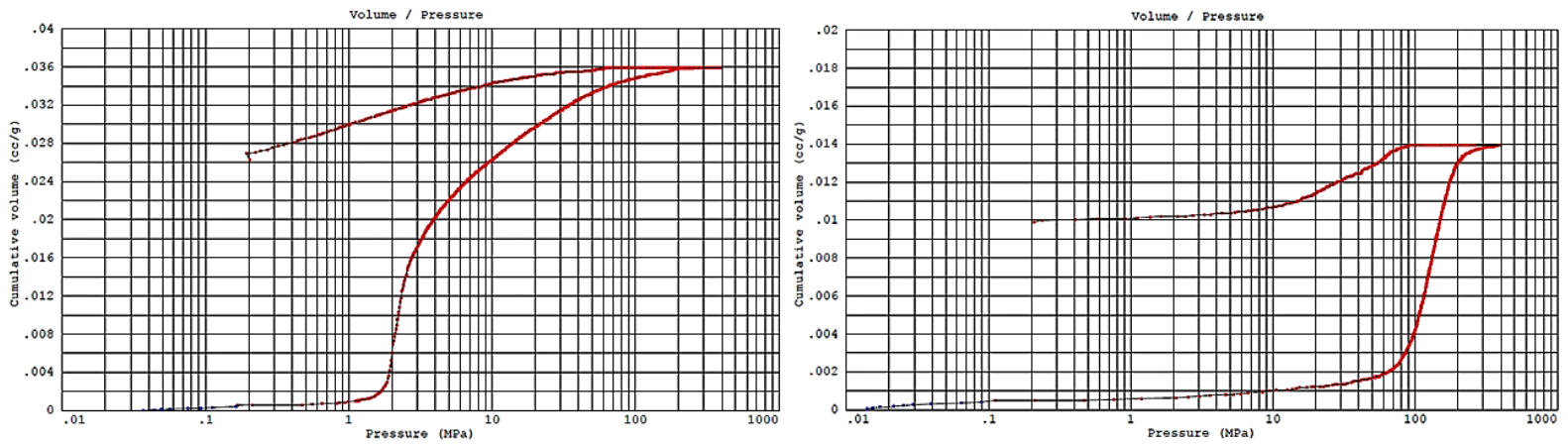

Figure 4. Capillary pressure curves from Hunya-1 well samples

After integrating the pressure values into the Purcell model, water / gas pressure values and curves are obtained (Figure 5). It is important, however, that these calculations are valid only in water-wet rocks at the time of writing, the method is under further development.
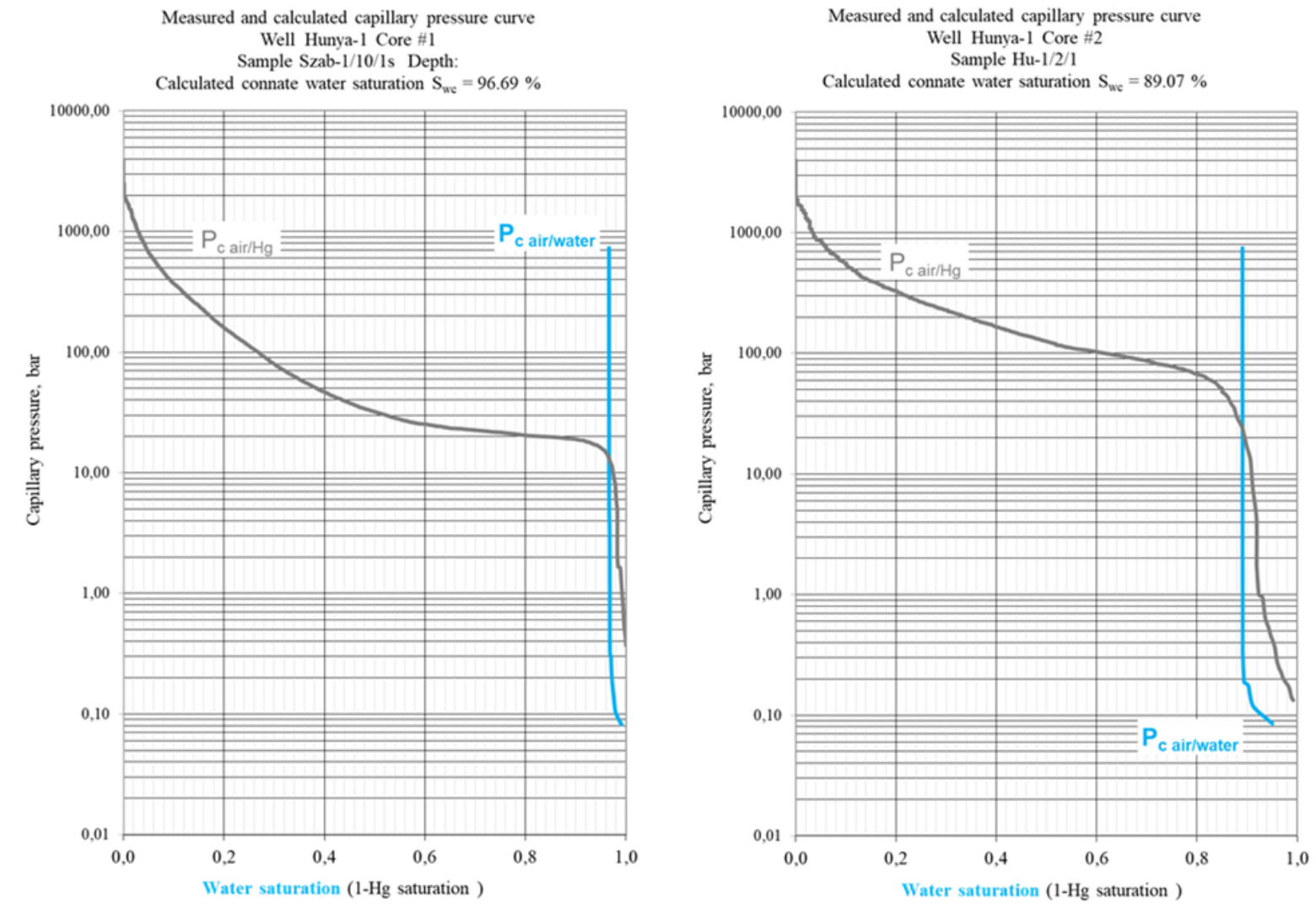

Figure 5. Capillary pressure curves (blue) based on the Purcell model 
By plotting the pressure curves, the readings show how high the residual water saturation values are in these types of reservoirs. The results are summarized in Table $\mathbf{1}$ and

Table 2 which can be found in Appendix 1. For both models, as well as for the validation well, the dependence on porosity and the most common pore size was examined.

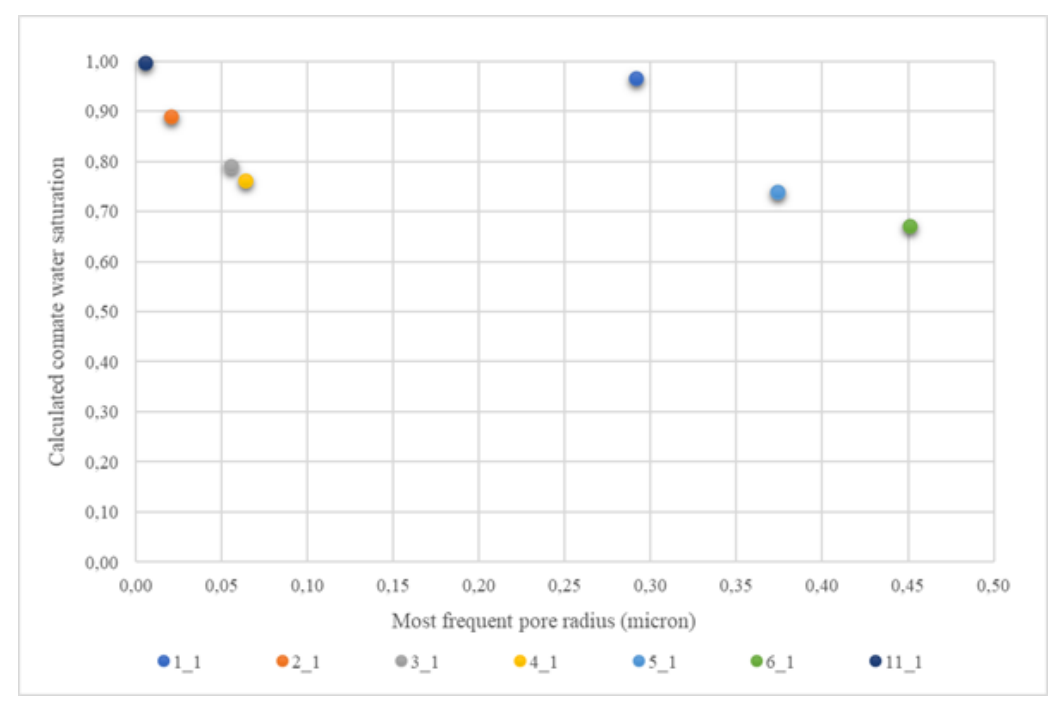

Figure 6. Calculated connate water saturation as a function of most frequent pore radius in Hunya-1 well

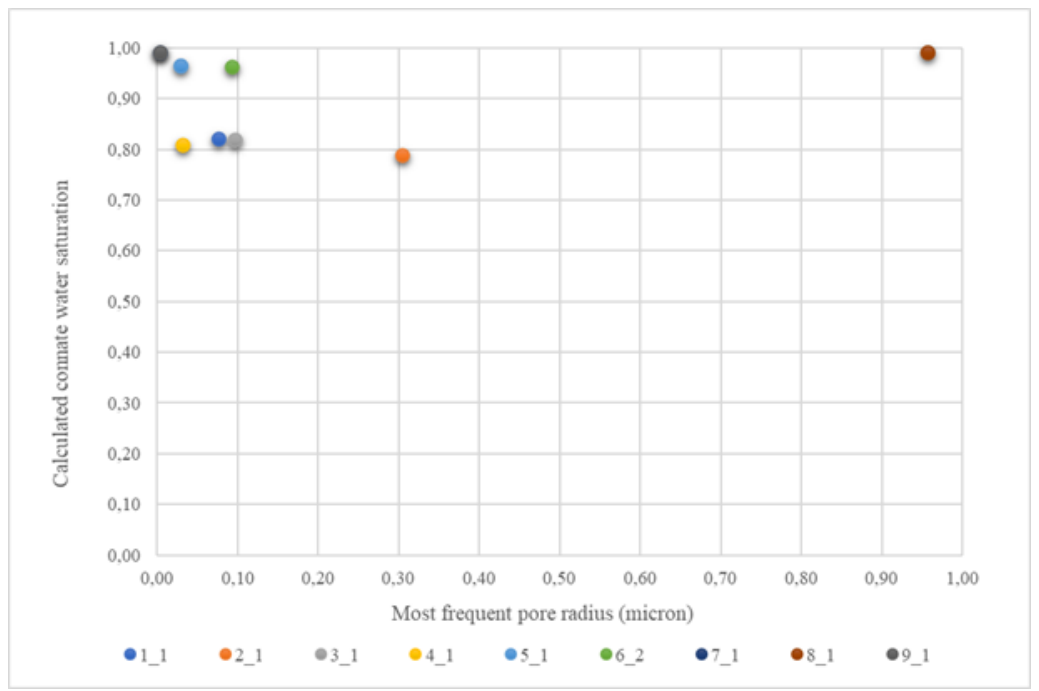

Figure 7. Calculated connate water saturation as a function of most frequent pore radius in Köröstarcsa-5 well

The calculated CWS values of the samples from Hunya-1 and Köröstarcsa-5 wells are plotted as a function of MFPR in Figure 6 and Figure 7. On both, it can be seen to be greater than 67\%. Figure 8 and Figure 9 represent the same values as a function of Mercury porosity. 


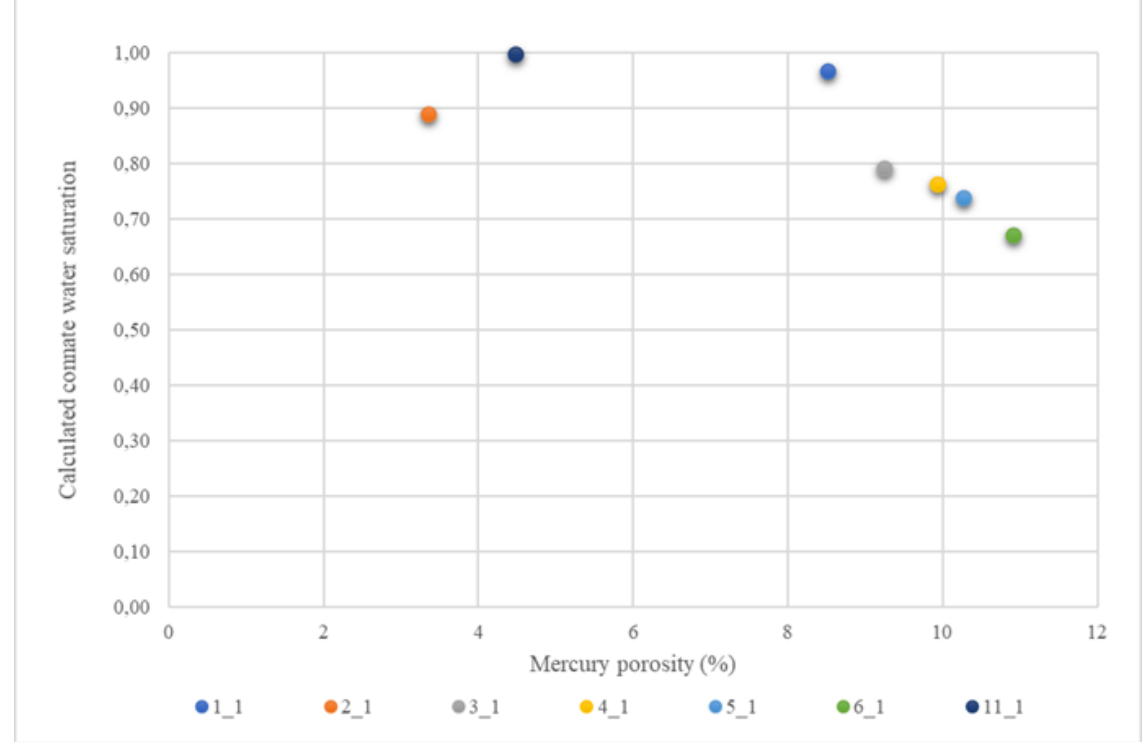

Figure 8. Calculated connate water saturation as a function of Mercury porosity in Hunya-1 well

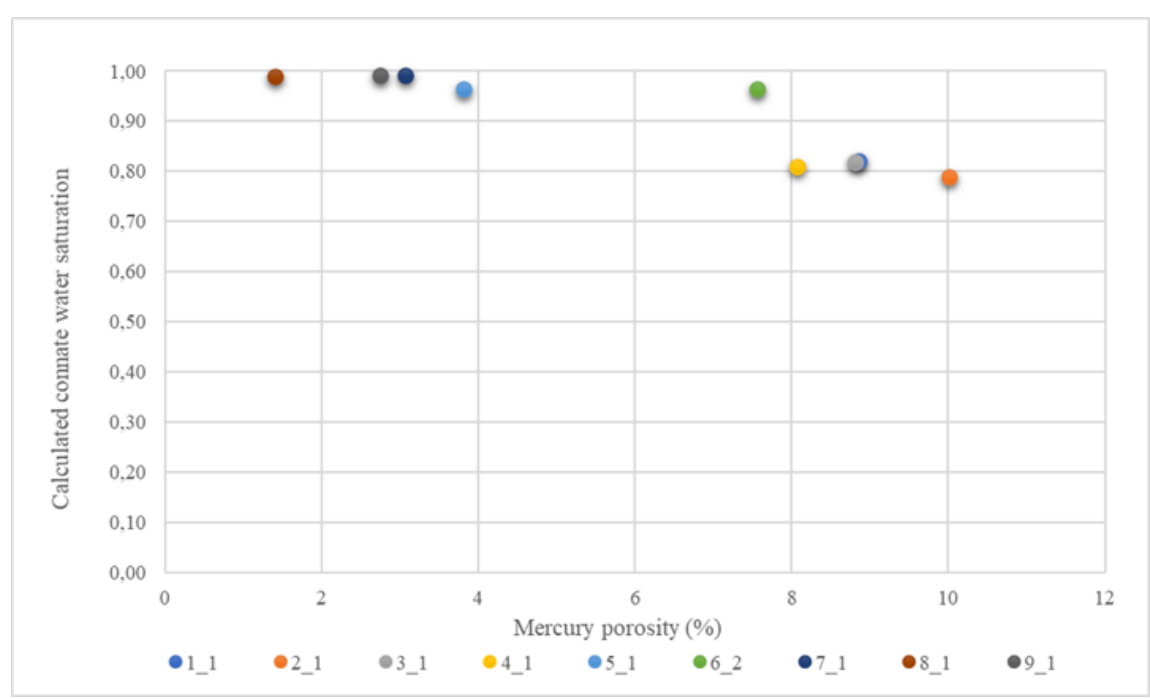

Figure 9. Calculated connate water saturation as a function of Mercury porosity in Köröstarcsa-5 well

It can be said that no specific connections can be drawn from MFPR or porosity alone based on the number of samples available. A much causal relationship can be seen between the pore size distribution and CWS values which explains more suitably the possible differences. On one hand, pore size distribution is not a single value, and on the other hand, as it has been shown, it can be error-prone in many cases (ranges above 10 microns), so corrected pore size distributions are the most suitable for the interpretation of CWS values. Ranges of the calculated values correlate well with the published results of other unconventional researches in Hungary [3] and with the data included in the final research reports [4]. 


\section{Summary}

As a part of unconventional reservoir sample investigation, it has been shown that connate water saturation can be surprisingly high, with a minimum of $65 \%$. Gas resource of such reservoirs and production of these wells are significantly affected by CWS. The exploration of the pore structure and the determination of CWS provide strong basis for understanding the transport processes in the rock, which contributes to the theoretical basis of production difficulties. With regards to the production issues of gas occurrences possessing high CWS, it cannot be ignored that only a small part of the pore space can be filled by gas, which determines the value of the gas resources. Furthermore, if there is mobile water in the pore space in addition to $\mathrm{CW}$, the mobility of the gas becomes even more reduced which poses production technology challenges.

\section{Acknowledgements}

The research was carried out in the framework of the GINOP-2.3.2-15-2016- 00010 "Development of enhanced engineering methods with the aim at utilization of subterranean energy resources" project of the Research Institute of Applied Earth Sciences of the University of Miskolc in the framework of the Széchenyi 2020 Plan, funded by the European Union, co-financed by the European Structural and Investment Funds.

\section{References}

[1] Remeczki, F.: Connate water saturation determination with a mathematical method - in case of Hungarian tight gas reservoir samples, Interdisciplinary Doctoral Conference 2020, University of Pécs, 28. November 2020.

[2] Purcell, W. R.: Capillary pressures - Their measurement using Mercury and the calculation of permeability therefrom, Petroleum Transactions, AIME, Texas, February 1949, Volume 1. no. 2. pp. 39-48. https://doi.org/10.2118/949039-G

[3] Bódi, T.: A Makói árok kőzeteinek petrofizikai tulajdonságai a nem konvencionális szénhidrogén termelés tükrében, Szénhidrogének a Makói árokban, Budapest, 29. January 2008.

[4] Zárójelentés a 101. Battonya - Pusztaföldvár kutatási területen végzett szénhidrogénkutatási tevékenységröl, 5. kötet, Szolnok, 2010 
Mathematical method application to determine connate water saturation...

\section{Appendixes}

\section{Appendix 1}

Table 1. Measurement and calculation result regarding the two model wells

\begin{tabular}{|l|c|c|c|c|}
\hline \multicolumn{1}{|c|}{ Sample } & Depth & Mercury porosity & $\begin{array}{c}\text { Most frequent } \\
\text { pore radius }\end{array}$ & $\begin{array}{c}\text { Calculated connate } \\
\text { water saturation }\end{array}$ \\
\hline Hu-1-1E-1 & meter & $\%$ & micrometer & - \\
\hline Hu-1-2-1 & 3037,0 & 8,5 & 0,2913 & 0,967 \\
\hline Hu-1-3-1 & 3033,0 & 3,3 & 0,0205 & 0,891 \\
\hline Hu-1-4-1 & 3033,0 & 9,3 & 0,0554 & 0,792 \\
\hline Hu-1-5-1 & 3033,0 & 10,3 & 0,0639 & 0,763 \\
\hline Hu-1-6-1 & 3172,0 & 10,9 & 0,3743 & 0,738 \\
\hline Hu-1-11-1 & 3172,0 & 4,5 & 0,4509 & 0,671 \\
\hline Köt-5-1-1 & 2894,0 & 8,9 & 0,0760 & 0,998 \\
\hline Köt-5-2-1 & 2894,0 & 10,0 & 0,3042 & 0,822 \\
\hline Köt-5-3-1 & 2894,0 & 8,8 & 0,0968 & 0,789 \\
\hline Köt-5-4-1 & 3043,0 & 8,1 & 0,0309 & 0,819 \\
\hline Köt-5-5-1 & 3043,0 & 3,8 & 0,0288 & 0,810 \\
\hline Köt-5-6-2 & 3043,0 & 7,6 & 0,0927 & 0,964 \\
\hline Köt-5-7-1 & 3227,0 & 3,1 & 0,0033 & 0,964 \\
\hline Köt-5-8-1 & 3227,0 & 1,4 & 0,9578 & 0,992 \\
\hline Köt-5-9-1 & 3227,0 & 2,7 & 0,0037 & 0,990 \\
\hline & & & & 0,991 \\
\hline
\end{tabular}


Table 2. Measurement and calculation result regarding the 'validation' well

\begin{tabular}{|l|c|c|c|c|}
\hline Szab-1_9_1 & 3269,80 & 9,7356 & 0,2177 & 0,7290 \\
\hline Szab-1_8_5 & 3269,60 & 9,9128 & 0,3599 & 0,7252 \\
\hline Szab-1_7_1 & 3271,10 & 9,2606 & 0,2693 & 0,7042 \\
\hline Szab-1_6_3 & 3271,75 & 9,9797 & 0,2122 & 0,7442 \\
\hline Szab-1_5_2 & 3274,25 & 10,7891 & 0,3007 & 0,6641 \\
\hline Szab-1_3_1 & 3279,60 & 7,3316 & 0,0441 & 0,8622 \\
\hline Szab-1_3_2 & 3279,60 & 6,0180 & 0,0648 & 0,8703 \\
\hline Szab-1_3_3 & 3279,60 & 6,2853 & 0,0352 & 0,8731 \\
\hline Szab-1_3_4 & 3279,60 & 6,6128 & 0,0206 & 0,8992 \\
\hline Szab-1_1_1 & 3283,20 & 11,1700 & 0,3007 & 0,7009 \\
\hline Szab-1_1_2 & 3283,20 & 10,4200 & 0,3082 & 0,7569 \\
\hline Szab-1_1_3 & 3283,20 & 11,4800 & 0,2333 & 0,6924 \\
\hline Szab-1_1_4 & 3283,20 & 9,6000 & 0,1891 & 0,7672 \\
\hline Szab-1_1_5 & 3283,20 & 9,5874 & 0,1516 & 0,8037 \\
\hline Szab-1_10_1 & 3516,45 & 2,3698 & 0,0085 & 0,9373 \\
\hline Szab-1_11_1 & 3605,15 & 7,0885 & 0,0771 & 0,8085 \\
\hline Szab-1_12_1 & 3600,05 & 7,8541 & 0,1758 & 0,8019 \\
\hline Szab-1_12_2 & 3600,05 & 7,9635 & 0,0513 & 0,8103 \\
\hline Szab-1_13_1 & 3596,35 & 9,9984 & 0,5543 & 0,5546 \\
\hline Szab-1_13_2 & 3596,35 & 9,8805 & 0,4570 & 0,5504 \\
\hline
\end{tabular}




\section{Appendix 2}

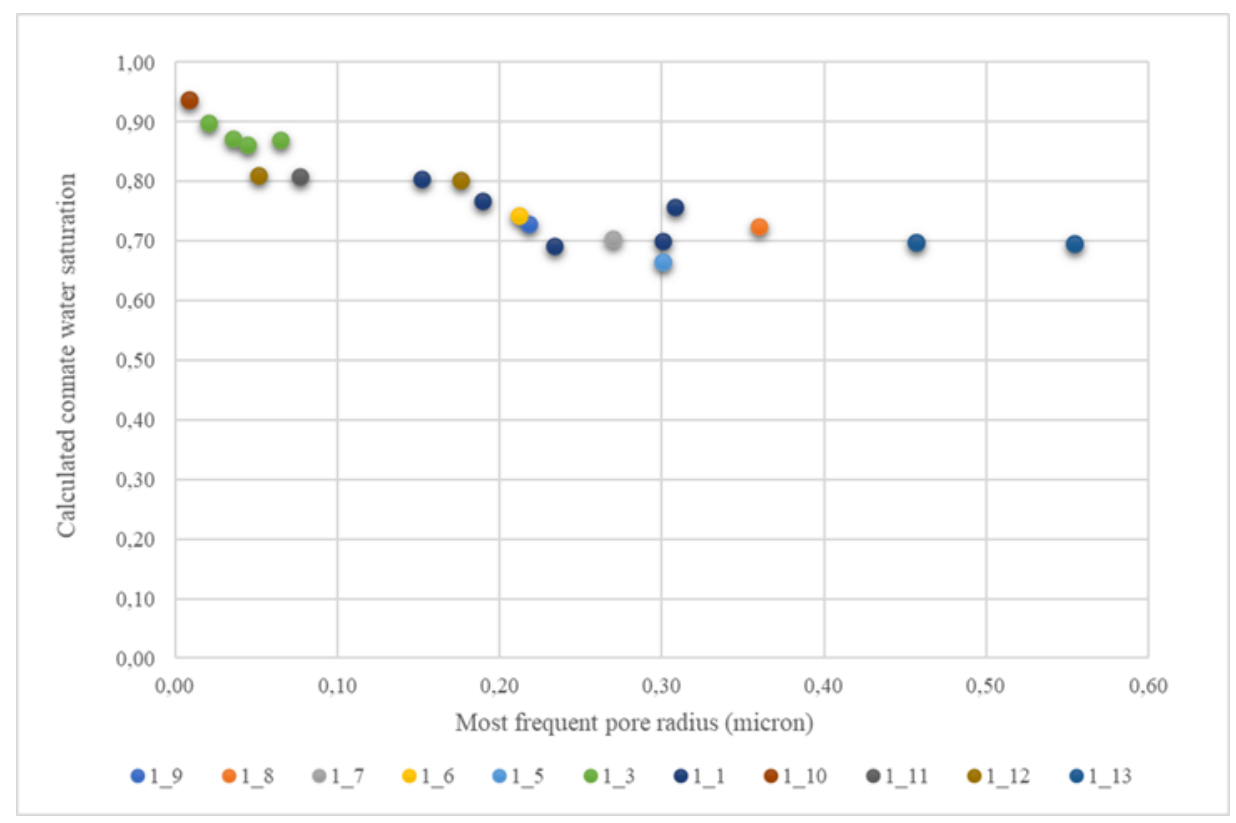

Figure 10. Calculated connate water saturation as a function of most frequent pore radius in Szabadkígyós-1 well

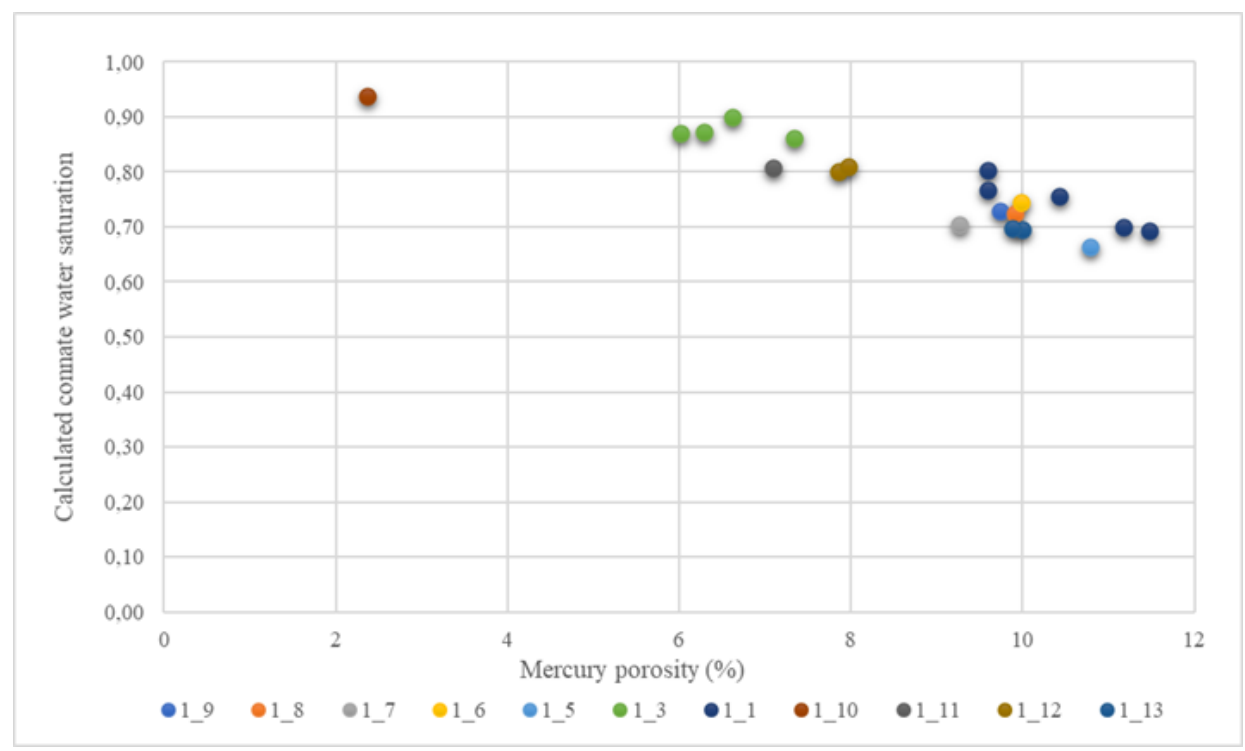

Figure 11. Calculated connate water saturation as a function of Mercury porosity in Szabadkigyós-1 well 